\title{
The influence of multifamily apartment building occupants on energy and water consumption - the preliminary results of monitoring and survey campaign
}

\author{
Karol Bandurski ${ }^{1, *}$, Miłosz Hamerla ${ }^{2}$, Jowita Szulc ${ }^{3}$, and Halina Koczyk ${ }^{1}$ \\ ${ }^{1}$ Poznan University of Technology, Faculty of Civil and Environmental Engineering, Institute of \\ Environmental Engineering, ul. Berdychowo 4, 60-965 Poznań, Poland \\ ${ }^{2}$ HM-PROJEKT Miłosz Hamerla, 77-400 Złotów, Poland \\ ${ }^{3}$ Freelance engineer, Poland
}

\begin{abstract}
Occupants' attitudes and behavior have a significant influence on energy and water consumption in buildings. To provide more robust solutions, energy efficient applications should consider occupant-building interaction. However, there is a question to be answered: which aspects of lodging and occupant behavior cause the most substantial increase in consumption of these mediums. Thus, the aim of this study is to investigate the influence of household characteristics and occupants' behavior on level and variability in utilities consumption. The study uses the results of a measuring campaign and the questionnaire. The measuring campaign was carried out to monitor the consumption of energy used for space heating and domestic hot water, as well as electricity, gas and water. The questionnaire specifically focused on household characteristics and occupants' behavior. The research was carried out in four apartment buildings, all consisting of more than 100 apartments. Data from approximately 100 households was gathered and analyzed; the survey's respond rate was almost $50 \%$. A quantitative analysis of the results confirms the assumption that both household characteristics and occupants' behavior (e.g. the use of heating control) are important factors for utilities consumption. Further work with the obtained data is planned in terms of including of greater number of apartments, assessment of ventilation effectiveness, as well as analysis of heat transfer between the apartments.
\end{abstract}

\section{Introduction}

Approach to operation of residential buildings has a significant influence on use of energy, water and air pollution in large cities in developing countries. With its households responsible for $25 \%$ of direct energy consumption, Poland could serve as a good example [1]. At the same time, the share of heating and cooling households in emissions of $\mathrm{CO}_{2}$ is $10 \%$, while their share in emission of particle matter $\left(\mathrm{PM}_{10}\right.$ and $\left.\mathrm{PM}_{2.5}\right)$ is nearly $48 \%$ [2].

*Corresponding author: karol.bandurski@put.poznan.pl 
This is the area with a great potential in terms of reducing overall energy consumption and air pollution in cities. It is recognized, that development of reliable energy-saving and lowemission technological solutions in civil engineering requires certain consideration of the human factor in analysis [3], as it is one of the main factors that can have impact on buildings operation [4]. The same applies to water consumption, especially in the context of smart cities concept [5]. However, the answer to the question of what behavior is responsible for it requires some further research. Similar studies have been already carried out in different regions of the world, e.g. [6-11]

This article contains the analysis of readings and survey data, obtained in Poland (a developing country) and tries to find answers to the following questions:

1. What level of variability is observed in the use of water, gas, electricity and heat energy in the analyzed apartments?

2. Is this variability in consumption of energy observed mainly between households or does it also fluctuate over time?

3. What causes these differences between the households?

4. Is there any interdependence between the consumption of particular mediums by particular apartments?

\section{Methodology}

The analysis was conducted using the results of measurements taken in multifamily communal buildings (blocks of flats) in a large city in Poland. The data was obtained in 2015-2016 for the following mediums: heat energy for space heating (SH), domestic hot water (DHW), electric energy (EE), gas (G) and water (W). The data covers about one hundred apartments from four buildings of similar design that differ only by numbers of stairways and positioning. The sources of data were:

- questionnaires (respond rate 50\%);

- weekly readings of EE, W and G consumption by households (8 weeks);

- daily readings of EE, W and G consumption by households (9 days);

- daily readings of heat energy used by households for SH and DHW (during one year).

This article is the first, brief analysis of the obtained data, so for SH and DWH the measurements only apply for internal apartments of buildings which differ only by their positioning. All of them comprise two rooms, a kitchen and a bathroom, with the total area of $46 \mathrm{~m}^{2}$ and are characterized by heat transfer coefficient of about 31 [W/K]. In total there are 32 such apartments in the monitored buildings, but it was not possible to gain complete sets of data for all of them. For separate analysis of all other mediums (EE, W, G), all available measurements were taken into account (not only those coming from internal apartments).

Major part of the analysis was carried out using box plots where: the $x$ sign is the mean of the data set, the horizontal band inside the box is the median, and bottom and top of the box show the first (Q1) and the third (Q3) quartiles. Meanwhile, the vertical lines (whiskers) represent the lowest and the highest values of data set within the range from $\mathrm{Q} 1-1.5 *(\mathrm{Q} 3-\mathrm{Q} 1)$ to $\mathrm{Q} 3+1.5 *(\mathrm{Q} 3-\mathrm{Q} 1)$.

\section{Results}

The results of the study are presented below as answers to questions placed in the introduction, and are grounded on the analyzed data. 


\subsection{Differentiation by the mediums use}

Fig. 1 shows differentiation in consumption of energy (with differentiation by objectives and mediums) and water (by analyzed apartments). It turns out, even without data from apartments with extreme values of obtained measurements, the differences in energy use between apartments can reach factor five mark and six for water.

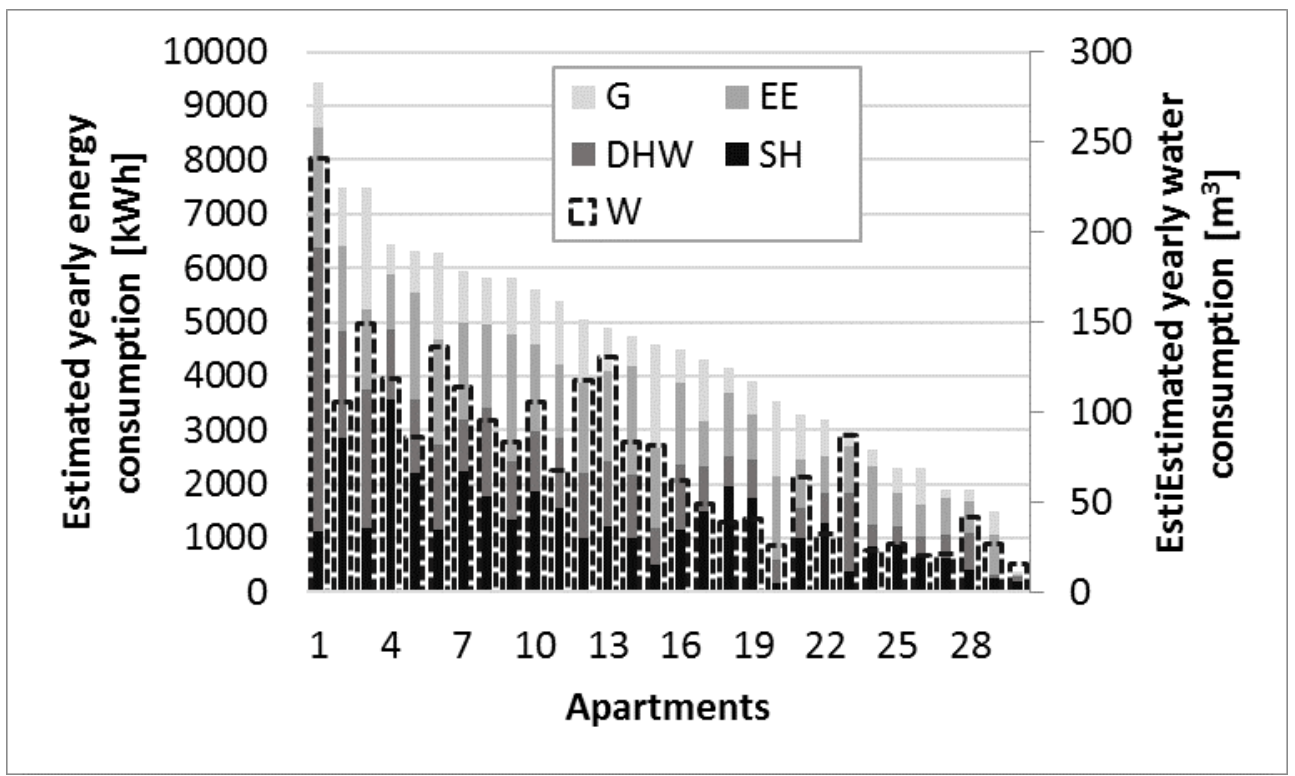

Fig. 1. Estimated yearly energy and water consumption for analysed apartments.

\subsection{Weekly vs daily variations in consumption as compared to differences between particular households}
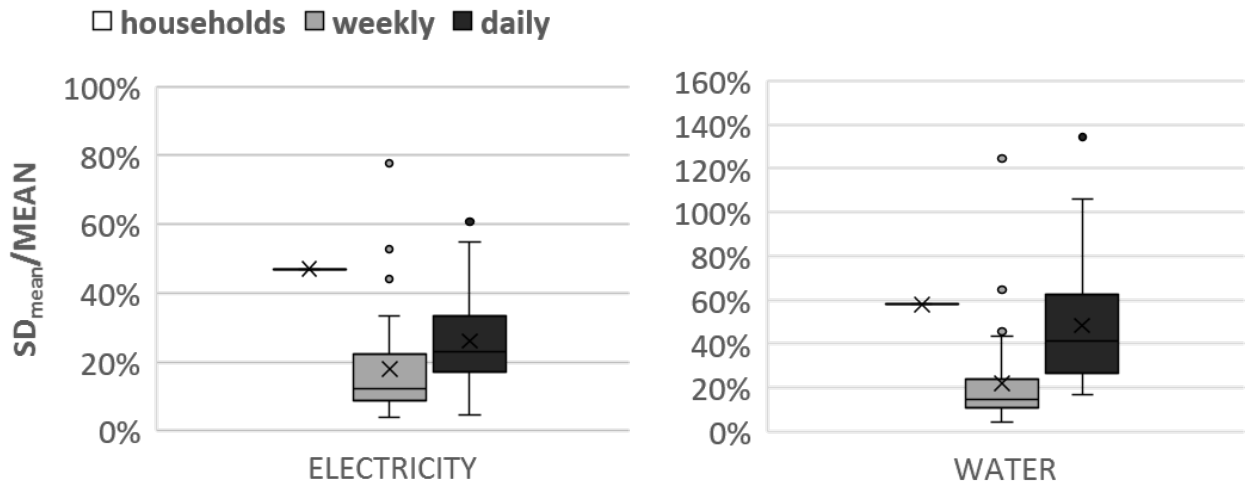

Fig. 2. Weekly, daily and households diversity in energy and water consumption.

For every household with relevant data available, mean daily and weekly values of electric energy and water consumption were defined on the grounds of the measurements taken, as well as the mean standard deviation of these values. Then the mean and mean standard deviation of the use of EE, W and G over the measurement period for all households was 
determined. The ratio of $S D_{\text {mean }}$ to the mean was adopted as the measure of variation. Fig. 2 shows the obtained values; one can notice that independently of the medium, the largest differentiation can be found between households, and the most common recurrence can be observed in monitored weeks for a given household. The differentiation between monitored daily data is more distinct than between weeks. At the same time the value of $\mathrm{SD}_{\text {mean }} / \mathrm{MEAN}$ for $24 \mathrm{~h}$ use differ greatly for particular households. Similar results were obtained by analysis of variations in $\mathrm{G}$ use, as well as by using a different measure of variation: the ratio of the difference between the highest and the lowest value to the median.

\subsection{What does cause households consumption diversity?}

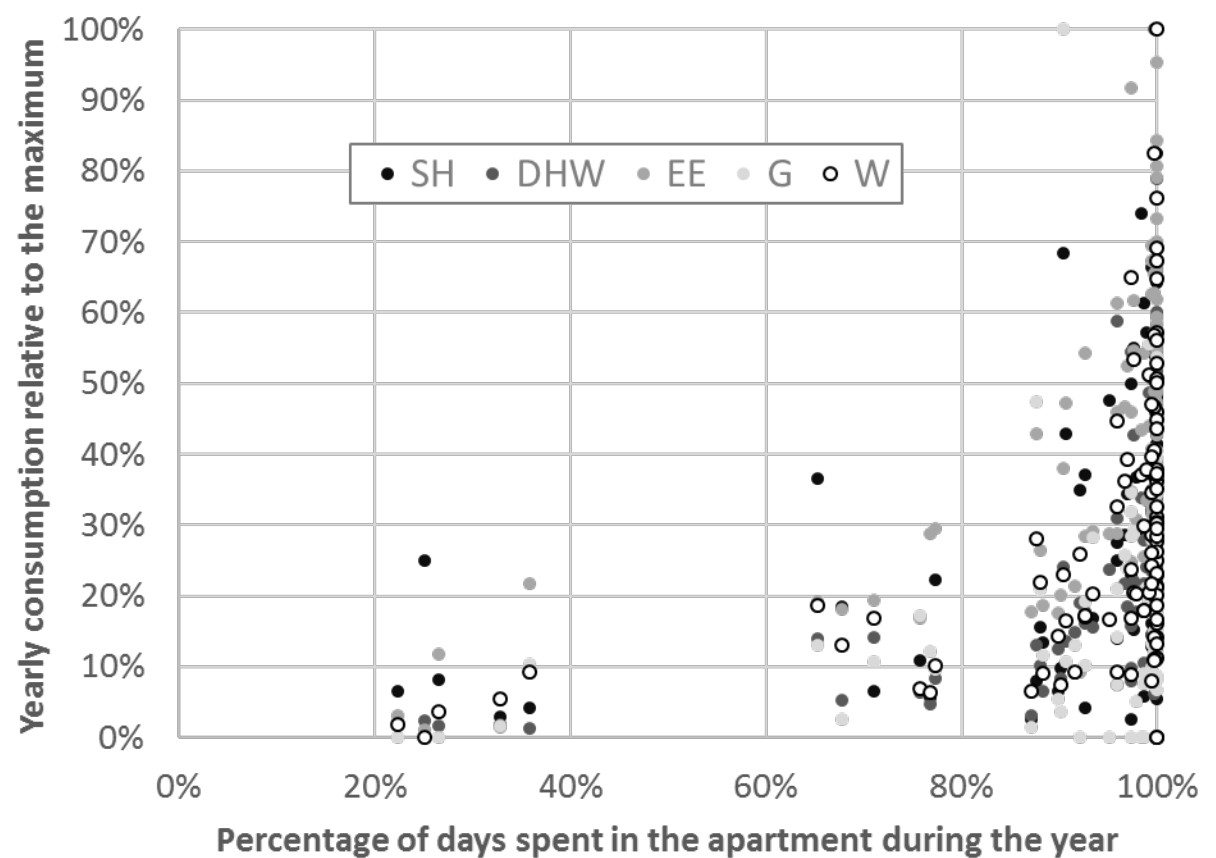

Fig. 3. The use of mediums as the function of number of days in the year when the apartment was occupied (lived in).

The primary reason for variations in the mediums use for particular apartments is the fact that some of them were occupied only for certain periods of time during the year. It can be stated on the grounds of data obtained from 24 hour readings of heat meters in the apartments, as shown in Fig. 3.

Another very important factor is the number of people in particular households. The use of most mediums grew with the increase of this number - the fastest rise was in EE and the slowest was in G. A very interesting correlation was observed in case of SH use, as shown in Fig. 4 - left. The rising trend was observed only for single- or two-person household, meanwhile decrease was observed in three- and more person households. This phenomenon might have appeared because of two reasons. First, three or four-personal households are usually families who prefer an active lifestyle and rarely stay at home, and thus can use the heating less (Fig. 4 - right). Second, the greater the household, the higher internal heat gains are obtained. These two reasons may be interlaced. The results of measurement campaign 
also imply inappropriate ventilation of the rooms. For hygienic reasons multi-personal households require more intensive ventilation. Yet, as $\mathrm{SH}$ use in the most populated apartments is the lowest, it can be assumed that the fresh air inflow was over-reduced by the residents.

$\square 1 \square 2 \square 3 \square 4$

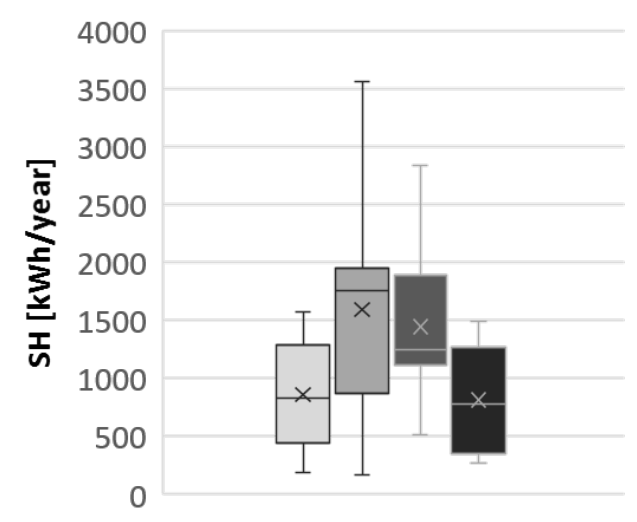

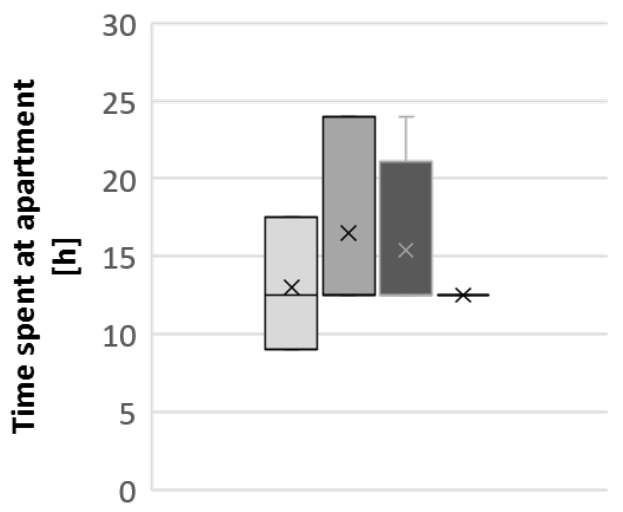

Fig. 4. The use of SH by households and time (during 24 hours) the residents spent in the apartment as the function of number of persons in households.

$\square 1 \square 2 \square 3$

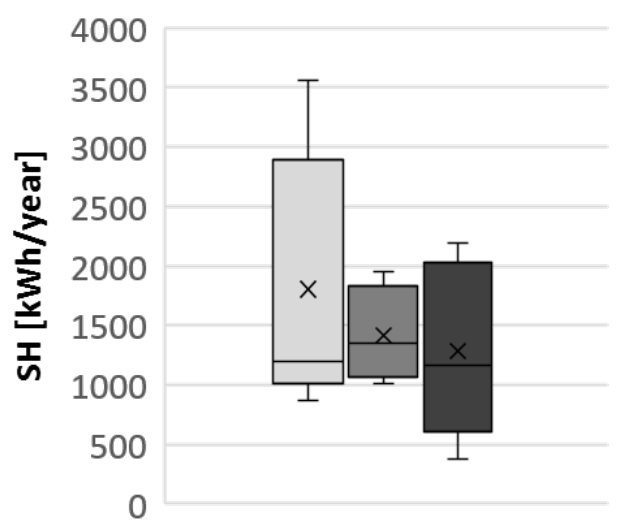

$\square$ automatic $\square$ manual

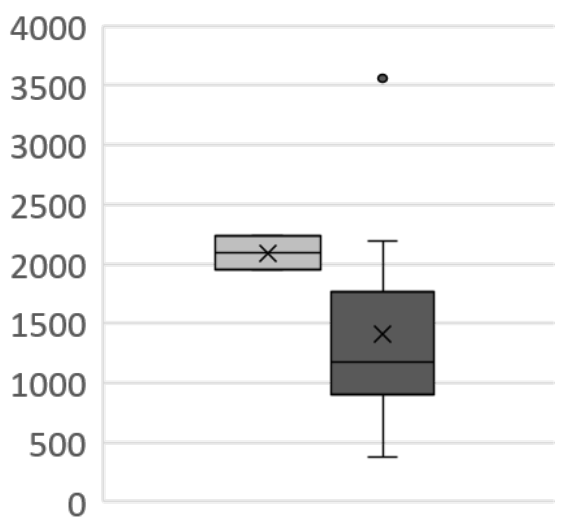

Fig. 5. Use of SH by households as the function of number of rooms without heating and the method of heating adjustment.

The use of SH is also influenced by method of adjustment of heating and ventilation devices. The following three aspects were chosen to be discussed.

- The number of heated rooms - the apartments under analysis comprise four rooms (kitchen, bathroom and two other rooms). Fig. 5 shows that the fewer rooms are heated the lower the average use of SH is. The effect is reinforced by the fact that apartments with lower temperature are heated by adjacent apartments with higher temperature. 
- The method of heating adjustment - the residents can use in their apartments both programmable setting units and thermostatic valves. Fig. 5 shows significant variations in SH use in apartments where heating is adjusted manually, as compared to those where programmable setting units are used. The probable reason for such differences could be the assumption that use of programmable unit alone leads to heating of all rooms, while manual adjustment of valves allows for meeting the real needs only.

- Adjustments by opening and closing windows (Fig. 6). The results of the measurement campaign show how excessive limiting of ventilation can decrease $\mathrm{SH}$ use, and lack of coordination in terms of ventilating and heating rooms can increase $\mathrm{SH}$ use.
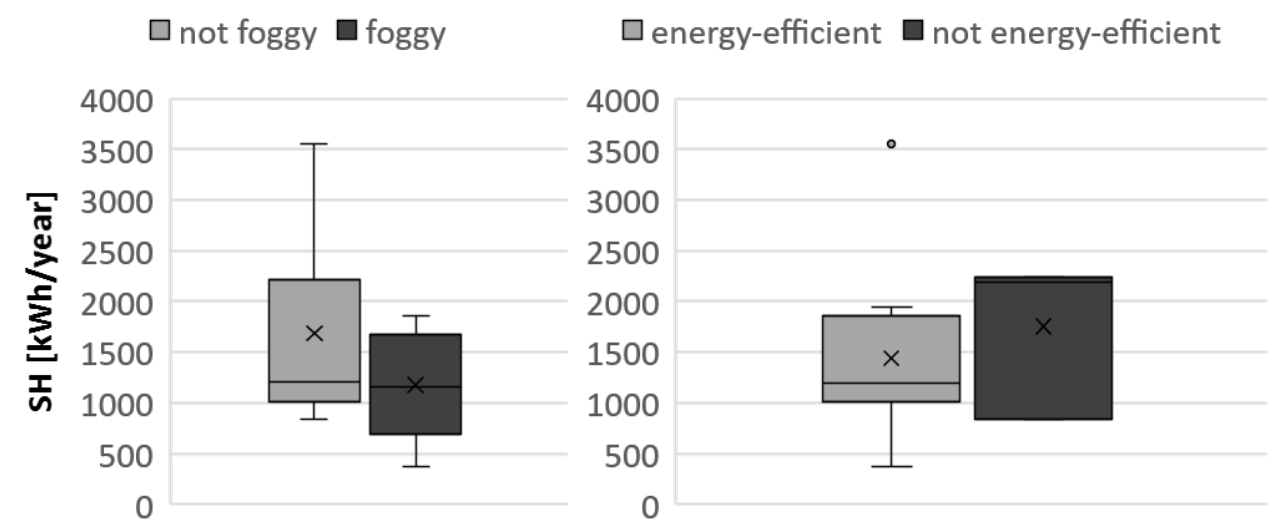

Fig. 6. SH use and ventilation. The diagram on the left presents SH use with the division into apartments where windows are steamed up in winter and those where they are not. The diagram on the right presents $\mathrm{SH}$ use with the division into apartments whose residents avoid simultaneous airing and heating of rooms (energy efficient use) and those whose residents do not care.

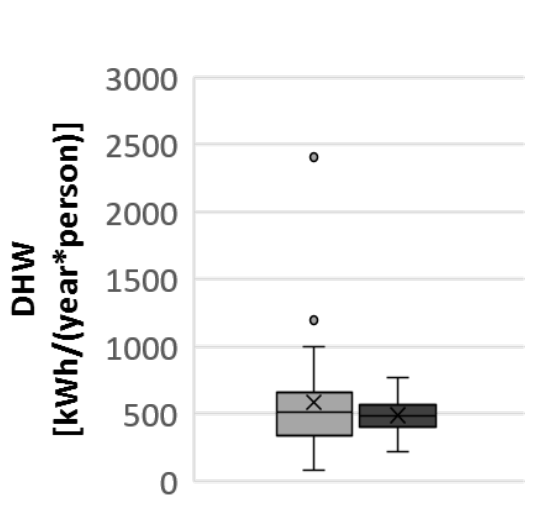

\section{$\square$ w/o dishwasher $\square$ dishwasher}

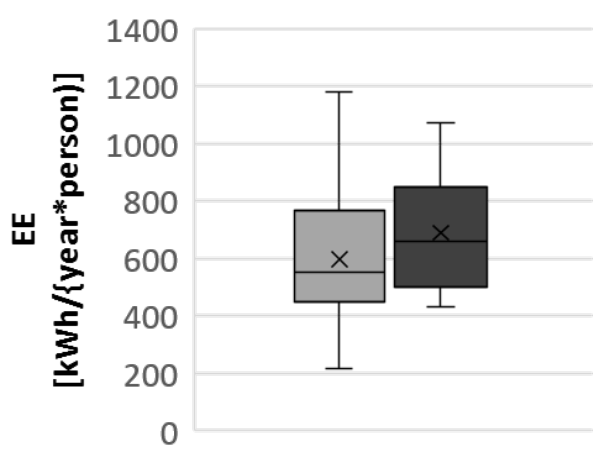

Fig. 7. The impact of dishwasher on the use of DHW and EE.

The use of dishwasher can serve as a good example of interdependence of different mediums use. Fig. 7 shows the use of $D H W$ and EE per person by households with and without a dishwasher. One can see significant differences in use of EE, however, it is not so 
definite for $D H W$ ( $W$ use has similar profile). The cause for such variations to appear can be ineffectiveness of dishwashers as compared to manual washing up. However, it has to be mentioned that households with dishwashers are characterized by narrower range of variations in DHW and EE use. The obtained readings show that higher effectiveness of manual washing up is strongly dependent on particular households, while the use of dishwashers gives more "homogeneous" results.

\subsection{Correlation between utilities consumption}

If the use of mediums depends on lifestyle, it probably would be possible to notice correlation in particular mediums use by households. As presented in Table 1, such correlations do exist. The most evident one is between DHW and $\mathrm{W}$, as well as the one between DHW and EE or W and EE.

Table 1. Coefficient of determination $\left(\mathrm{R}^{2}\right)$ for correlation between the use of analyzed mediums by households.

\begin{tabular}{|c|c|c|c|c|c|}
\cline { 2 - 6 } \multicolumn{1}{c|}{} & SH & DHW & EE & G & W \\
\hline SH & 1 & 0.18 & 0.16 & 0.10 & 0.23 \\
\hline DHW & $\mathrm{x}$ & 1 & 0.40 & 0.16 & 0.68 \\
\hline $\mathbf{E E}$ & $\mathrm{x}$ & $\mathrm{x}$ & 1 & 0.14 & 0.57 \\
\hline G & $\mathrm{x}$ & $\mathrm{x}$ & $\mathrm{x}$ & 1 & 0.13 \\
\hline W & $\mathrm{x}$ & $\mathrm{x}$ & $\mathrm{x}$ & $\mathrm{x}$ & 1 \\
\hline
\end{tabular}

\section{Conclusion}

The article discusses in brief some of the results of mediums' use measurement campaign in multifamily buildings: cold water (W), electric energy (EE), gas $(\mathrm{G})$, energy for space heating (SH) and domestic hot water (DHW). The presented data was analyzed in terms of differentiation in the use of mediums and possible reasons of such variability. It was proved that occupants can have significant influence on consumption of the mediums: characteristics of households as well as methods of heating and ventilation adjustment. On the basis of the conducted analysis it can be also stated that the problem of ineffective natural ventilation or its ineffective use is widespread and common. This is why development of modern solutions for energy-efficient multifamily constructions, which is still in high demand, requires an appropriate design not only in terms of the building's shape and its technical equipment, but also methods of control and adjustment of microclimate inside in the context of needs and behavior of its occupants.

This article's follow-up will be comprehensive analysis of data obtained from measurements and questionnaires. It will include normalized data concerning SH use, as this type of data for apartments with various heat loss coefficients cannot be compared directly. The data will also allow for estimation of ventilation-related heat losses for particular apartments and assessment of its effectiveness as well as analysis of the influence of adjacent apartments on each other in terms of heat losses/gains. 


\section{Acknowledgment}

We would like to thank the following people for supporting our measuring campaign: Matgorzata Fengler and Patrycja Mazurkiewicz - students; Mr. Jacek - keeper of the buildings; Sylwia Hemmerling from ZZN Sp. z o. o.; Wojciech Michalak, Agnieszka Staniewska, Matgorzata Piwińska from ZKZL Sp. z o. o and Łukasz Filip from Kamstrup.

\section{References}

1. W. Tkaczyk, Eds., Gospodarka paliwowo-energetyczna w latach 2014 i 2015 (GUS, Warszawa 2016)

2. Rachunki ekonomiczne środowiska, 2016. [Online]. Available: http://stat.gov.pl/obszary-tematyczne/srodowisko-energia/srodowisko/rachunkiekonomiczne-srodowiska, $7,1 . \mathrm{html}$

3. P. Hoes, J.L.M. Hensen, M. G.L.C. Loomans, B. de Vries, D. Bourgeois, Energy Build. 41, 3 (2009)

4. H. Yoshino, S. Chen, Eds., Total Energy Use in Buildings: Analysis and Evaluation Methods (Annex 53), (IEA EBC An. AECOM 2016)

5. F. Mizuki, K. Mikawa, H. Kurisu, Hitachi Rev. 61, 3 (2012)

6. O. Guerra-Santin, L. C. M. Itard, Build. Res. Inf. 38, 3 (2010)

7. R. K. Andersen, 10th International Conference on Healthy Buildings (2012)

8. R. Haas, H. Auer, P. Biermayr, Energy Build. 27, 2 (1998)

9. A. Al-Mumin, O. Khattab, G. Sridhar, Energy Build. 35, 6 (2003)

10. J. Ouyang, K. Hokao, Energy Build. 41, 7 (2009)

11. G. M. Huebner, J. Cooper, K. Jones, Energy Build. 66 (2013) 